\title{
The Role of Acetaldehyde in Mediating the Deleterious Effect of Ethanol on Pyridoxal 5'-Phosphate Metabolism
}

\author{
LAWRENCE Lumeng, Departments of Medicine and Biochemistry, Indiana University \\ School of Medicine and Veterans Administration Hospital, \\ Indianapolis, Indiana 46202
}

A B S T RAC T Previous studies in vivo and with isolated perfused rat livers have suggested that the deleterious effect of ethanol on hepatic pyridoxal $5^{\prime}$ phosphate metabolism is mediated by acetaldehyde. Inasmuch as acetaldehyde has no effect on the synthesis of pyridoxal phosphate, it has also been postulated that acetaldehyde accelerates pyridoxal phosphate degradation by displacing this coenzyme from binding proteins, which protect it against hydrolysis. To test these hypotheses, studies have been performed with isolated rat hepatocytes, subcellular fractions of rat liver, and human erythrocytes. Ethanol oxidation lowered the pyridoxal phosphate content of isolated liver cells when acetaldehyde oxidation was inhibited by either disulfiram or prior treatment of rats with cyanamide. Additions of $7.5 \mathrm{mM}$ acetaldehyde alone at 40-min intervals to cell suspensions decreased hepatic pyridoxal phosphate content only slightly because acetaldehyde was rapidly metabolized. However, when acetaldehyde oxidation and reduction were inhibited by cyanamide treatment and by 4-methylpyrazole and isobutyramide, respectively, a $40 \%$ decrease in hepatic pyridoxal phosphate content was observed in $80 \mathrm{~min}$ of incubation.

In equilibrium dialysis experiments, acetaldehyde, 7.5 and $15 \mathrm{mM}$, displaced protein-bound pyridoxal phosphate in undialyzed hepatic cytosol and in hemolysate supernate containing added pyridoxal phosphate. In the presence of alkaline phosphatase, acetaldehyde accelerated the degradation of pyridoxal phosphate in dialyzed hemolysate supernate and hepatic cytosol with added pyridoxal phosphate. Acetaldehyde also inhibits tyrosine aminotransferase. The kinetics of inhibition were mixed competitive-noncompeti-

This work was presented in part at the 46th Annual Meeting of the Central Society for Clinical Research, Chicago, 2 November 1973, and at the National Institute on Alcohol Abuse and Alcoholism Workshop on "Alcohol and Nutrition," Indianapolis, 26-27 September 1977.

Received for publication 11 January 1978 and in revised form 16 March 1978. tive with respect to pyridoxal phosphate. These observations support the hypothesis that the deleterious effect of ethanol oxidation on pyridoxal phosphate metabolism is mediated at least in part by acetaldehyde which displaces this coenzyme from protein binding, thereby enhancing its degradation.

\section{INTRODUCTION}

Vitamin $\mathrm{B}_{6}$ deficiency, as evidenced by a decreased level of plasma pyridoxal $5^{\prime}$-phosphate (PLP), ${ }^{1}$ is frequently encountered in alcoholic patients both with $(1,2)$ and without (3) liver disease. Although inadequate dietary intake may be a contributory factor, it has been shown that alcohol ingestion interferes with the net conversion of parenterally administered pyridoxine to plasma PLP (1). In experimental animals, PLP in plasma is derived almost entirely from liver, and its concentration is determined both by hepatic synthesis and by degradation (4). We have reported that the oxidation of alcohol by isolated perfused rat livers curtails both the release of PLP into the perfusion medium and lowers hepatic PLP content (5). These deleterious effects of alcohol on PLP metabolism are abolished by 4-methylpyrazole, a specific inhibitor of alcohol dehydrogenase, suggesting that acetaldehyde may be the causative agent (5). Indeed, incubation of human erythrocytes with 0.05-1 mM acetaldehyde impairs the net conversion of pyridoxine to PLP (3). Because acetaldehyde does not alter the rate of PLP synthesis (3), it was postulated that acetaldehyde accelerates PLP degradation.

In the normal regulation of vitamin $B_{6}$ metabolism in liver, the cellular content of PLP is governed principally by protein binding on the one hand and by hydrolysis of unbound (free) PLP by alkaline phosphatase on the other (6). Because acetaldehyde, like PLP, is capable of forming Schiff's bases with protein

${ }^{1}$ Abbreviations used in this paper: PLP, pyridoxal 5'-phosphate; TEA-HCl, triethanolamine hydrochloride. 
amino groups, it was postulated that acetaldehyde accelerates PLP degradation by displacing PLP from protein binding. This hypothesis has now been tested in experiments with isolated rat hepatocytes, subcellular fractions of rat liver, and human erythrocytes. The efficacy of acetaldehyde in displacing PLP from protein binding of PLP has also been directly measured.

\section{METHODS}

Preparation of isolated rat hepatocytes. Male SpragueDawley rats $(150-250 \mathrm{~g})$, maintained for at least $1 \mathrm{wk}$ on standard laboratory chow (Wayne Lab-Blox; Allied Mills, Inc., Chicago, Ill.) ad lib., were fasted $12-18 \mathrm{~h}$ before use for the isolation of liver parenchymal cells. The pyridoxine content of the diet was $8.1 \mu \mathrm{g} / \mathrm{g}$. In some experiments, rats were injected intraperitoneally with cyanamide, $0.1 \mathrm{mg} / \mathrm{kg}$, $1 \mathrm{~h}$ before the preparation of isolated liver cells (7). The method for isolating liver cells was similar to the procedure described by Seglen (8). The major steps included the addition of $2.5 \mathrm{mM} \mathrm{CaCl}$ to the Hanks' medium during collagenase digestion and the further dispersion of the minced liver with hyaluronidase $(8 \mathrm{mg} / 50 \mathrm{ml}$ of medium) after perfusion with collagenase. The isolated parenchymal cells were $>98 \%$ pure. $90-95 \%$ of the liver cells excluded trypan blue and exhibited intracellular $\mathrm{K}^{+}$concentration of $134 \pm 10.5$ meq/liter $(n=10)$. The cells were morphologically intact by electron microscopy (9) and were active in amino acid transport (10), gluconeogenesis (10), and synthesis of enzymes inducible by hormones (11). These measures of viability were maintained with little change for at least $4 \mathrm{~h}$ after isolation.

Preparation of supernate and membrane fractions of human erythrocytes. Venous blood was collected from healthy human volunteers with $2 \mathrm{mM}$ EDTA as an anticoagulant. After separation from plasma and buffy coat, the erythrocytes were washed twice with $0.15 \mathrm{M} \mathrm{NaCl}$ at $4^{\circ} \mathrm{C}$, and hemolyzed by either hypotonic lysis or freeze-thaw. In the former procedure, the washed erythrocytes were hemolyzed with 10 vol of $12 \mathrm{mM}$ triethanolamine hydrochloride (TEA$\mathrm{HCl}$ ), $\mathrm{pH} 7.4$, at $4^{\circ} \mathrm{C}$. After $10 \mathrm{~min}$ of intermittent mixing, the hemolysate was centrifuged at $30,000 \mathrm{~g}$ for $30 \mathrm{~min}$ to separate the supernatant fraction from the erythrocyte membranes. To prepare hemolysate by freeze-thaw, the washed erythrocytes were quick-frozen in an acetone-dry ice bath and thawed four times. The membrane ghosts were then separated by centrifugation at $100,000 \mathrm{~g}$ for $90 \mathrm{~min}$. For studies that required recombination of supernate and membrane fractions, the membrane fraction derived from hypotonic lysis of erythrocytes was washed six or more times with the TEA-HCl buffer until the erythrocyte membranes became colorless. Before recombination, the hemolysate supernate was dialyzed extensively in $12 \mathrm{mM}$ TEA-HCl buffer and the membrane ghosts were disrupted by sonication, employing a model 1,000 Insonator (Savant Instruments, Inc., Hicksville, N. Y.) (20 $\mathrm{kHz}$ ) supplied with a half-inch sonohorn. The reference meter setting was 75 , and sonication was applied three times in 10-s pulses at $4^{\circ} \mathrm{C}$.

Preparation of cytosolic fraction and isolated plasma membranes from rat liver. Male Sprague-Dawley rats $(150-250 \mathrm{~g})$, fasted $12-18 \mathrm{~h}$, were used for the preparation of subcellular fractions. Cytosolic fraction and plasma membranes were prepared by the methods of Hogeboom (12) and of Ray (13), respectively.

Purification of tyrosine aminotransferase. Tyrosine aminotransferase was purified from rat liver as described by Granner and Tomkins (14). The procedure was carried out through the DEAE-cellulose chromatography step; at which point, the yield was $18-25 \%$ and the specific activity of the enzyme was 72-95 $\mathrm{U} / \mathrm{mg}$ protein. Tyrosine aminotransferase was resolved of its coenzyme (PLP) by dialysis for $18 \mathrm{~h}$ at $4^{\circ} \mathrm{C}$ against $0.1 \mathrm{M}$ potassium phosphate, $\mathrm{pH} 6.0$ (15).

Incubation conditions. All incubations were performed in Erlenmeyer flasks in a shaking water bath. The experiments were conducted in darkened rooms equipped with yellow fluorescent lights to minimize photodecomposition of PLP.

In the cell experiments, freshly isolated liver cells, 15-20 $\mathrm{mg}$ protein $/ \mathrm{ml}$, were incubated at $37^{\circ} \mathrm{C}$ in $7.5 \mathrm{ml} \mathrm{Krebs-}$ Henseleit medium containing $10 \mathrm{mM}$ pyruvate and $2.5 \mathrm{~g} / 100$ $\mathrm{ml}$ fatty acid free bovine serum albumin. The incubation flasks, sealed by rubber caps, were flushed with $95 \% \mathrm{O}_{2}$ and $5 \% \mathrm{CO}_{2}$ before adding ethanol or acetaldehyde. In the experiments with acetaldehyde, it was necessary to add acetaldehyde at 40 -min intervals because it was metabolized rapidly even when the cells were isolated from cyanamide-treated rats and incubated in the presence of 4-methylpyrazole and isobutyramide. The addition of reagents and the sampling of cell suspensions were carried out with Hamilton syringes (Hamilton Co., Reno, Nev.). At appropriate time intervals, $1-\mathrm{ml}$ aliquots of cell suspension were removed and centrifuged for $3 \mathrm{~min}$ at 1,000 $\mathrm{g}$ in a Sero-Fuge (Clay Adams, Div. of Becton, Dickinson \& Co., Parsippany, N. J.) to separate the cells from the medium. The medium was immediately deproteinated by adding $0.2 \mathrm{ml} 60 \% \mathrm{HClO}_{4}$ and used for acetaldehyde assay. The cell pellet was washed with $10 \mathrm{vol}$ of a cold Krebs-Henseleit medium and resuspended in $4 \mathrm{ml}$ of a cold $2 \mathrm{mM}$ phosphate buffer ( $\mathrm{pH}$ 7.4). The resuspended cells, 0.2 $\mathrm{ml}$ aliquots, were then added to $2.5 \mathrm{ml} 2 \mathrm{mM}$ phosphate buffer ( $\mathrm{pH} 7.4)$ and immediately precipitated with $0.3 \mathrm{ml} 75 \%$ trichloroacetic acid. After discarding the protein precipitate, the supernate was extracted with ether and then assayed for PLP.

Analyses. PLP and acetaldehyde were assayed enzymatically with tyrosine apodecarboxylase and aldehyde dehydrogenase, respectively $(3,16)$. Hemoglobin was determined as cyanmethemoglobin (17). Protein concentrations were measured by the method of Lowry et al. (18).

During the purification of hepatic tyrosine aminotransferase, enzyme activity was assayed by measuring the rate of formation of $p$-hydroxybenzaldehyde at $37^{\circ} \mathrm{C}(19)$. The final reaction mixture contained $2.4 \mathrm{ml}$ of $0.125 \mathrm{M}$ potassium phosphate $(\mathrm{pH} \mathrm{7.6)}$ and $7 \mathrm{mM}$ L-tyrosine, $0.06 \mathrm{ml}$ of $0.5 \mathrm{M} \alpha$ ketoglutarate, $0.03 \mathrm{ml}$ of $5 \mathrm{mM}$ PLP, and $0.3 \mathrm{ml}$ of tyrosine aminotransferase. The latter was diluted in a buffer that contained $0.125 \mathrm{M}$ potassium phosphate $(\mathrm{pH} 7.6), 5 \mathrm{mg} / \mathrm{ml}$ bovine serum albumin, $1 \mathrm{mM}$ EDTA, and $1 \mathrm{mM}$ dithiothreitol. The reaction was started by the addition of enzyme, and stopped at 2.5 and $5 \mathrm{~min}$ by the addition of $0.21 \mathrm{ml}$ of $10 \mathrm{~N}$ $\mathrm{KOH}$. The final mixture, kept for $30 \mathrm{~min}$ at $37^{\circ} \mathrm{C}$, was then read at $331 \mathrm{~nm}$ against a "zero time" blank prepared by the addition of $\mathrm{KOH}$ to the reaction components before tyrosine aminotransferase. The molar absorbancy of the product, $p$ hydroxybenzaldehyde, is $19,900 / \mathrm{M} \cdot \mathrm{cm}$. $1 \mathrm{U}$ of enzyme activity is the quantity that catalyzes the formation of $1 \mu \mathrm{mol}$ $p$-hydroxyphenylpyruvate/min.

In the course of this work, it was found that acetaldehyde interfered with this assay method. Thus an alternative method, the modified Briggs assay (20), was employed when acetaldehyde was present in the reaction mixture. The assay condition was as described above but the reactions were terminated by adding $0.21 \mathrm{ml}$ of $50 \%$ trichloroacetic acid. To this solution, $1.8 \mathrm{ml}$ of water, $1 \mathrm{ml}$ of $1 \mathrm{~g} / 100 \mathrm{ml} \mathrm{K \textrm {K } _ { 2 }} \mathrm{PO}_{4}$, and $1 \mathrm{ml}$ of molybdate solution containing $5 \mathrm{~g} / 100 \mathrm{ml}$ ammonium molybdate in $5 \mathrm{~N} \mathrm{H}_{2} \mathrm{SO}_{4}$ were added. The final mixture was 
allowed to stand at room temperature for $1 \mathrm{~h}$ and then centrifuged to remove any precipitate. The blue color of the molybdate complex was read at $850 \mathrm{~nm}$ with a molar absorbancy of $4,100 / \mathrm{M} \cdot \mathrm{cm}$. The Briggs assay, although less sensitive, agreed well with the assay based on $p$-hydroxybenzaldehyde measurement.

Equilibrium dialysis. These studies were carried out in dialysis tubings with a molecular weight exclusion limit of $10,000-20,000$. Dialysis was performed at $4^{\circ} \mathrm{C}$ in stoppered flasks to prevent evaporation of acetaldehyde. Photodecomposition of PLP was minimized by wrapping the flasks in aluminum foil.

Reagents. Cyanamide, disulfiram, isobutyramide, essentially fatty acid-free bovine albumin, PLP, aldehyde dehydrogenase, and tyrosine apodecarboxylase were purchased from Sigma Chemical Co., St. Louis, Mo. 4-Methylpyrazole was obtained from K and K Laboratories, Inc., Plainview, N. Y. Collagenase and hyaluronidase were purchased from Worthington Biochemical Corp., Freehold, N. J. The apodecarboxylase was further purified as described previously (3). Reagent grade acetaldehyde was redistilled immediately before use.

Statistical analyses. Student's $t$ test was used to determine the significance of the difference between mean values.

\section{RESULTS}

Effect of ethanol and acetaldehyde on the PLP content of isolated liver cells. The effect of ethanol oxidation was first examined in liver cells isolated from untreated rats (Fig. 1). In contrast to our previous findings in perfused livers, PLP content was not affected by the addition of ethanol alone. However, when disulfiram was also added to the medium or when

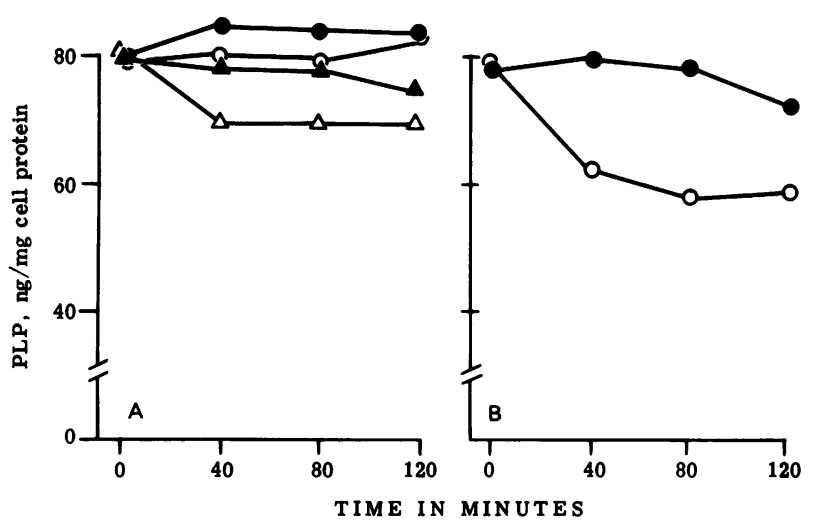

Figure 1 Effect of ethanol oxidation on the cellular content of PLP in isolated hepatocytes prepared from untreated and cyanamide-treated rats. Isolated hepatocytes from untreated and cyanamide-treated rats were incubated as described in Methods. (A) Cells from an untreated rat were incubated without other additions $(O)$, with $0.1 \mathrm{mM}$ disulfiram $(O)$, with $50 \mathrm{mM}$ ethanol $(\Delta)$, and with ethanol plus disulfiram $(\triangle)$. In four experiments with ethanol plus disulfiram, the mean decrease in cellular PLP at 120 min was $16 \%(P<0.001)$. (B) Cells from a cyanamide-treated rat were incubated with $(O)$ and without $50 \mathrm{mM}$ ethanol (O). In four experiments with cells prepared from cyanamide-treated animals, ethanol oxidation decreased cellular PLP $16-25 \%$ at $120 \mathrm{~min}(P<0.001)$. cells were isolated from cyanamide-treated rats, significant decreases in cellular PLP content were observed at the end of 2 -h incubation $(n=4$ for each condition, $P<0.001$ ). Both disulfiram and cyanamide are potent inhibitors of liver aldehyde dehydrogenases. Thus, it appeared that to demonstrate an effect of acetaldehyde on PLP metabolism in isolated cells, it is necessary to inhibit the further metabolism of acetaldehyde.

The effect of acetaldehyde on PLP content of isolated liver cells prepared from untreated and cyanamide-treated rats is shown in Fig. 2. With cells isolated from untreated animals, the addition of $7.5 \mathrm{mM}$ acetaldehyde at 40 -min intervals lowered the cellular content of PLP only slightly (mean decrease was $13 \%$ at the end of 2 -h incubation, $n=4, P<0.01$ ). However, acetaldehyde was metabolized rapidly and its concentration decreased to $0-0.1 \mathrm{mM}$ at the end of each 40 min period. Acetaldehyde can be metabolized both by way of reduction to ethanol, catalyzed by alcohol dehydrogenase, and by way of oxidation to acetate catalyzed by aldehyde dehydrogenase. When the cells from untreated animals were incubated in the presence of isobutyramide and 4-methylpyrazole, potent inhibitors of alcohol dehydrogenase, the concentrations of acetaldehyde were $0.2-0.4 \mathrm{mM}$ at the end of each 40-min period and the decrease in cellular PLP was accordingly greater (mean decrease was $22 \%$ at the end of 2 -h incubation, $n=4, P<0.001$ ). When these inhibitors were added to cells prepared from cyanamidetreated rats, the acetaldehyde concentrations were maintained in the range of $2.8-7.5 \mathrm{mM}$ and cellular

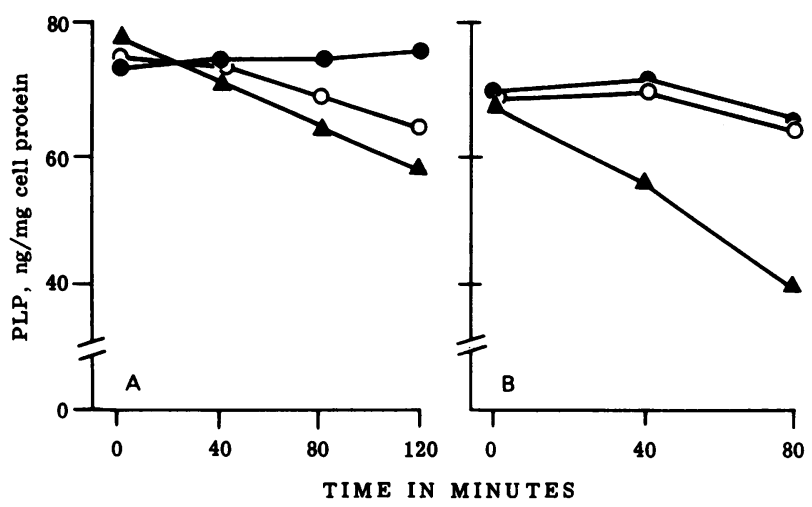

FIGURE 2 Effect of acetaldehyde metabolism on the cellular content of PLP in isolated hepatocytes prepared from untreated and cyanamide-treated rats. (A) Cells from an untreated rat were incubated without other additions $(\Theta)$, with $7.5 \mathrm{mM}$ acetaldehyde added at 40 -min intervals $(O)$, and with $7.5 \mathrm{mM}$ acetaldehyde added $40 \mathrm{~min}$ apart and in the presence of $0.15 \mathrm{mM} \mathrm{4-methylpyrazole} \mathrm{and} 1 \mathrm{mM}$ isobutyramide ( $\Delta$ ). (B) Cells from a cyanamide-treated rat were incubated without other additions $(\Theta)$, and with $0.75 \mathrm{mM}(O)$ and $7.5 \mathrm{mM}(\Delta)$ acetaldehyde added at 40 -min intervals in the presence of 4-methylpyrazole and isobutyramide. The results are representative of four experiments. 
PLP decreased $>40 \%$ (Fig. $2, n=4, P<0.001$ ). These data, therefore, indicate that under appropriate conditions, both ethanol and acetaldehyde can significantly alter the metabolism of PLP in the isolated liver cell.

Effect of acetaldehyde on protein-bound PLP in the soluble fractions of liver and erythrocytes. In liver, PLP is bound to a large number of PLP-dependent enzymes (21). Fig. 3 shows the effect of acetaldehyde on PLP binding by hepatic cytosol as studied by equilibrium dialysis. After dialysis for $24 \mathrm{~h}$, fully $20 \%$ of the cytosolic PLP, presumably free or loosely associated with proteins, was removed by dialysis in the absence of acetaldehyde. In the presence of 7.5 and $15 \mathrm{mM}$ acetaldehyde, both the rate and amount of PLP removal by dialysis were increased.

Fig. 4 shows the results of a similar experiment performed with the hemolysate supernate of erythrocytes. PLP was added to the hemolysate supernate before dialysis, and the amount remaining after dialysis to equilibrium at $19 \mathrm{~h}$ was measured. Acetaldehyde, 7.5 and $15 \mathrm{mM}$, reduced PLP content to 45 and $34 \%$ of the initial amounts present. In the absence of acetaldehyde, the amount remaining was $59 \%$. The amount of PLP lost from the dialysis bag in each instance was recovered almost quantitatively in the dialysate. These data, therefore, indicate the millimolar concentrations of acetaldehyde can effectively displace PLP from protein binding by both liver cytosol and the hemolysate supernate of erythrocytes.

Effect of acetaldehyde on PLP hydrolysis in a reconstructed system containing erythrocyte hemolysate supernate and cell membranes. PLP is actively de-

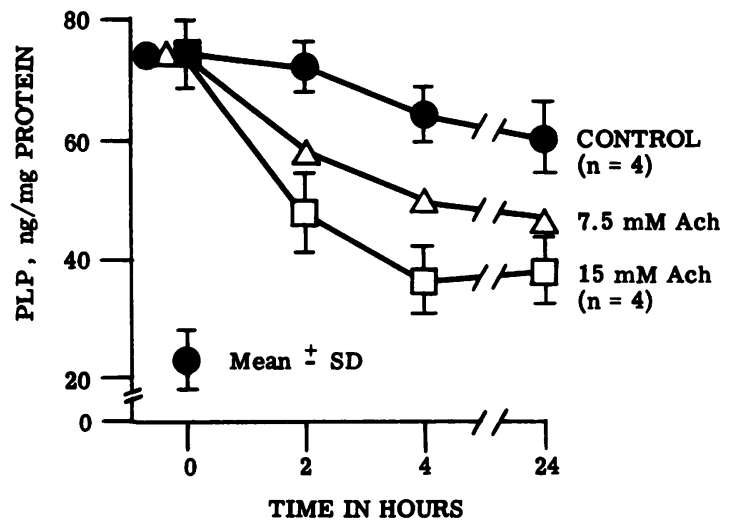

FIgure 3 Effect of acetaldehyde (Ach) on the PLP concentration of hepatic cytosol during dialysis. Liver cytosolic fraction, $8 \mathrm{ml}$ and containing $8.5 \mathrm{mg} / \mathrm{ml}$ protein, was put in each dialysis bag and dialyzed against $240 \mathrm{ml}$ of a $12 \mathrm{mM}$ TEA-HCl buffer ( $\mathrm{pH}$ 7.4). The change in PLP concentration in the cytosol was monitored during dialysis until equilibrium was reached. At equilibrium, the mean PLP concentration in the presence of $15 \mathrm{mM}$ Ach was lower $(P<0.01)$ than that of the control. Based on protein measurements, there was no volume change during dialysis.

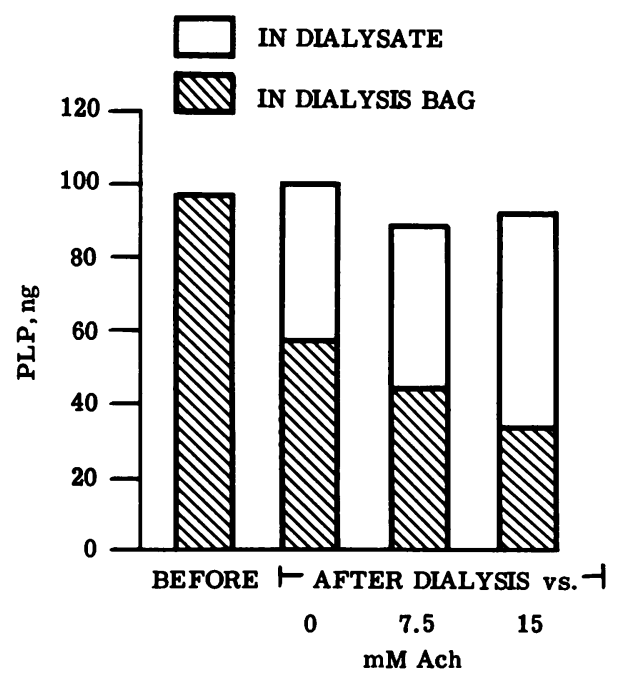

Figure 4 Effect of acetaldehyde on the PLP content of hemolysate supernate in equilibrium dialysis. The initial mixture contained $13.5 \mathrm{ml}$ of a hemolysate supernate $(2.59$ $\mathrm{g} / 100 \mathrm{ml}$ hemoglobin), $1.5 \mathrm{ml}$ of $2 \mathrm{M} \mathrm{KPi} \mathrm{(pH} \mathrm{7.4),} \mathrm{and} 0.1$ $\mathrm{ml}$ of PLP $(19 \mu \mathrm{g} / \mathrm{ml})$. This mixture was allowed to mix at $4^{\circ} \mathrm{C}$ for $4 \mathrm{~h}$. 0.75 of this mixture was put into each of three dialysis bags with varying amounts of acetaldehyde (Ach) added. Each mixture was then dialyzed against $15 \mathrm{ml}$ of a $0.2 \mathrm{M} \mathrm{KPi}$ ( $\mathrm{pH} 7.4$ ) buffer with varying concentrations of Ach. Dialysis was performed for $19 \mathrm{~h}$. There was no volume change across the dialysis membrane as determined by hemoglobin measurements. The results are the mean values of duplicate incubations and are representative of three experiments.

graded by the plasma membranes of erythrocytes and liver cells $(3,6)$. This PLP-hydrolyzing activity in hepatic plasma membranes has been characterized and shown to be a property of the nonspecific alkaline phosphatase enzyme which is associated with plasma membranes (22). Additionally, it has been shown that the binding of PLP to proteins protects it from degradation by alkaline phosphatase (6).

Fig. 5 shows the effect of acetaldehyde $(15 \mathrm{mM})$ on the hydrolysis of PLP in a reconstituted system of dialyzed hemolysate supernate and sonicated membrane ghosts. The amount of PLP present in dialyzed hemolysate supernate is small. This amount is tightly bound, and the addition of erythrocyte ghosts resulted in little or no change in PLP concentration after 80 min of incubation. As expected, acetaldehyde enhanced the degradation of this tightly bound PLP to only a slight extent. However, when PLP was added in vitro to the dialyzed hemolysate supernate to provide binding to low affinity sites, PLP hydrolysis by the membrane ghosts occurred more rapidly. Acetaldehyde, $10 \mathrm{mM}$, further accelerated this degradation rate and about 30 and $50 \%$ of the added PLP was hydrolyzed in 40 and $80 \mathrm{~min}$, respectively. It has been previously demonstrated that acetaldehyde does 


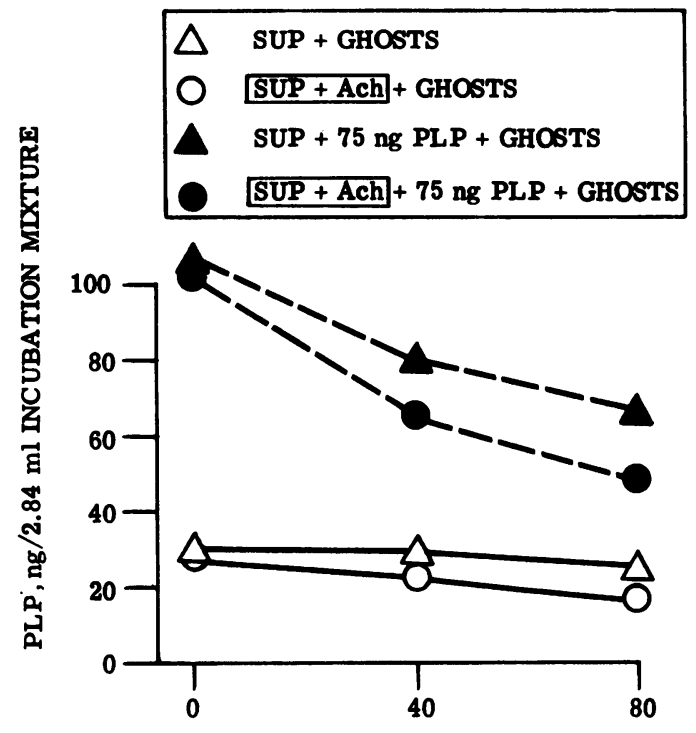

TIME IN MINUTES

Figure 5 Effect of acetaldehyde on the hydrolysis of PLP in a reconstituted system of dialyzed hemolysate supernate and sonicated erythrocytic ghosts. Hemolysate supernate, prepared by freeze-thaw method, was dialyzed for $16 \mathrm{~h}$ against a $12 \mathrm{mM}$ TEA-HCl (pH 7.4, hemolysate supernate/buffer volume ratio of $1 / 100$ ). The incubation mixtures contained $12 \mathrm{mM}$ TEA-HCl buffer (pH 7.4); $1.25 \mathrm{mM} \mathrm{MgCl}_{2}$; hemolysate supernate containing $330 \mathrm{mg}$ hemoglobin; and membrane ghosts derived from $0.12 \mathrm{ml}$ of packed erythrocytes. Where indicated, $75 \mathrm{ng}$ PLP and $15 \mathrm{mM}$ acetaldehyde (Ach) were also added. In the absence of hemolysate supernate, $75 \mathrm{ng}$ PLP in the free (unbound) form was hydrolyzed completely within 5 min (data not shown). The final volume of each mixture was 2.84 $\mathrm{ml}$. Reactions were started by adding the membrane ghosts. Temperature was $32^{\circ} \mathrm{C}$. The results are the mean values of duplicate incubations and are representative of three experiments.

not alter directly the PLP phosphatase activity of erythrocyte ghosts (3). Therefore, the mechanism by which acetaldehyde accelerates PLP degradation appears to be its displacement of PLP from low affinity protein binding sites, thereby allowing the unbound PLP to be rapidly hydrolyzed.

Similar results were obtained in experiments carried out with dialyzed hepatic cytosol and rat liver plasma membranes (data not shown), demonstrating that acetaldehyde enhances PLP degradation in liver by displacing bound PLP.

Effect of acetaldehyde on hepatic tyrosine aminotransferase. Tyrosine aminotransferase has a relatively low affinity for PLP (15). Additionally, the relative contributions of the various functional groups of PLP to the formation of the coenzyme-apoenzyme complex is known (23). Hence the effect of acetaldehyde on the activity of this enzyme was examined. Purified tyrosine aminotransferase activity was inhibited $50 \%$ by $17.5 \mathrm{mM}$ acetaldehyde. The kinetics of inhibition was mixed competitive-noncompetitive with respect to PLP (Fig. 6).

\section{DISCUSSION}

We have previously reported that ethanol oxidation decreases the hepatic content of PLP in isolated perfused rat livers (5). In the present study with isolated hepatocytes, ethanol oxidation has no demonstrable effect on cellular PLP content unless acetaldehyde oxidation was inhibited concomitantly (Fig. 1). These findings suggest that the perfused liver and isolated hepatocyte systems differ quantitatively in their ability to metabolize acetaldehyde. Data from the literature seem to support this conclusion. Thus, Crow et al. (24) have recently measured the accumulation of acetaldehyde in cell suspensions during ethanol oxidation and found its concentration to be low, in the range of $2 \mu \mathrm{M}$, but increasing to $50-180 \mu \mathrm{M}$ when $0.1 \mathrm{mM}$ disulfiram was added. On the other hand, Lindros et al. (25) have reported that the acetaldehyde level of isolated perfused rat livers was $150 \mu \mathrm{M}$ when the ethanol concentration in the perfusates was in the range of 16-32 mM. Importantly, the acetaldehyde concentrations of liver have been well demonstrated to be about $200 \mu \mathrm{M}$ in vivo during ethanol oxidation (26). The reason for these differences is unknown but is under investigation in our laboratory.

As would be expected from the above considerations, the addition of acetaldehyde to suspension of isolated hepatocytes from untreated rats resulted in only a small decrease in cellular PLP (Fig. 2), because acetaldehyde was rapidly metabolized by way of alcohol and aldehyde dehydrogenase in the isolated hepatocytes. The addition of 4-methylpyrazole and isobutyramide to the incubation of medium together with the use of cyan-

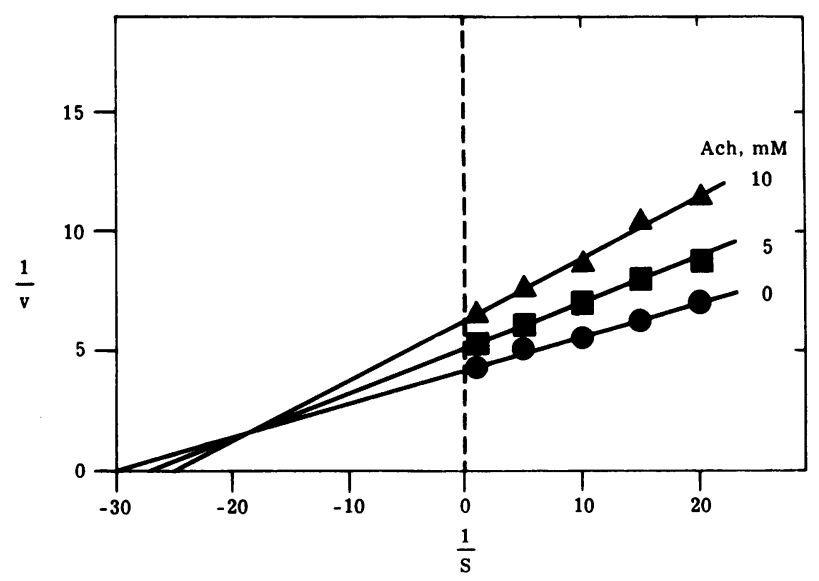

FIGURE 6 Effect of acetaldehyde (Ach) on tyrosine aminotransferase apoenzyme activity. The concentration of PLP was varied from $50 \mathrm{nM}$ to $1 \mu \mathrm{M}$. The results are representative of three experiments. 
amide-treated animals progressively increased the depletion of cellular PLP so that a $40 \%$ decrease was seen when acetaldehyde concentration was maintained in the range of $2.8-7.5 \mathrm{mM}$ (Fig. 2). These data support our previous hypothesis that acetaldehyde may be the toxic metabolite responsible for the detrimental effect of ethanol oxidation of PLP metabolism (3).

The studies with subcellular fractions of human erythrocytes and rat liver (Figs. 3 and 4 ) indicate that acetaldehyde is capable of displacing PLP from binding proteins in erythrocyte hemolysates and hepatic cytosol. This action renders PLP more susceptible to hydrolysis by the phosphatase enzyme located on erythrocytic and liver cell plasma membranes. Hepatic cytosol accounts for $70 \%$ of the PLP in liver (21) and contains a host of PLP-dependent enzymes with varying affinities for the coenzyme. When cytosol is dialyzed exhaustively in a TEA-HCl buffer or gel filtered on Sephadex G-150 (Pharmacia Fine Chemicals, Piscataway, N. J.), about $20 \%$ of the PLP can be removed. Presumably, this fraction of cytosolic PLP originates from PLP-dependent enzymes or proteins with low affinity for the coenzyme. Acetaldehyde affects principally these low affinity PLP-enzymes because its largest effect was demonstrated in undialyzed cytosol (Fig. 3).

Recent studies in our laboratories indicate that the distribution of PLP in liver is dispersed among many enzymes (21). Glycogen phosphorylase, aspartate aminotransferase, and alanine aminotransferase in combination account for $<30 \%$ of the PLP bound in liver cytosol. The identity of the PLP-enzymes and proteins responsible for the binding of the remainder of the PLP in cytosol remains unknown. This multiplicity of PLP-binding proteins in liver renders difficult the precise identification of the enzyme(s) most susceptible to the effect of acetaldehyde.

PLP binds to its apoenzymes by multipoint attachments (27). In addition to the labile azomethine linkage of the Schiff's base which forms between the aldehyde group of the coenzyme and lysyl residues of proteins, noncovalent interactions via the phosphate, the phenolic oxygen, and the heterocyclic nitrogen also play a role in the binding process. However, the relative strengths of these interactions in the various PLP-enzymes have not been systematically quantified. In the case of tyrosine aminotransferase, the $\Delta G^{\circ}$ value for the Schiff's base is only $2.8 \mathrm{kcal} / \mathrm{mol}$ (23). This free energy contribution is lower than that of the phosphate group, $7.1 \mathrm{kcal} / \mathrm{mol}$. This circumstance probably explains the high $\mathrm{K}_{\mathbf{1}}$ of acetaldehyde in the inhibition of tyrosine aminotransferase (Fig. 6). A number of aldehydes such as 4-nitrosalicylaldehyde, $m$ nitrobenzaldehyde, and 3-hydroxypyridine-4-aldehyde $(28,29)$, have been shown to compete for binding for the coenzyme site of PLP-dependent enzymes.
Thus, it is not surprising that acetaldehyde can also displace PLP from tyrosine aminotransferase and the supernatant proteins of erythrocytes and liver. The kinetic studies on tyrosine apoaminotransferase indicate mixed competitive and noncompetitive inhibition by acetaldehyde. Such a pattern can be interpreted as the occurrence of both the binding of acetaldehyde to the apoenzyme to form a binary complex that has a decreased affinity for PLP and the binding to the holoenzyme to form a ternary complex that is nonproductive (30). The mode of coenzyme-apoenzyme interaction in tyrosine aminotransferase differs significantly from some of the other PLP-enzymes, such as glycogen phosphorylase (31). In the latter, the covalent linkage due to Schiff's base formation appears to play a principal role in its cofactor-protein interaction. Studies are now in progress in our laboratories to study the effect of acetaldehyde on glycogen phosphorylase.

In considering the in vivo effects of acetaldehyde, quantitative data concerning its concentrations in blood and tissues are pertinent. As indicated earlier, acetaldehyde level in liver during ethanol oxidation is in the range of $200 \mu \mathrm{M}$ (26). Acetaldehyde level in the tail blood of rats is usually $<20 \mu \mathrm{M}$ but the level in arterial blood may attain concentrations up to $150 \mu \mathrm{M}$ (32). It is also known that after disulfiram or pyrogallol treatment $(33,34)$, venous blood acetaldehyde concentrations may reach levels as high as $2 \mathrm{mM}$. We have shown previously that acetaldehyde in the range of $0.05-1 \mathrm{mM}$ significantly inhibits the net conversion of PLP from pyridoxal or pyridoxine in erythrocytes which do not have the capacity to metabolize acetaldehyde (3). In the isolated hepatocyte experiments reported here, the presence of acetaldehyde at $0.1-0.4 \mathrm{mM}$ and $2.8-7.5 \mathrm{mM}$ resulted in $13-22 \%$ and $>40 \%$ decrease in cellular PLP, respectively (Fig. 2). Whereas the lower levels of acetaldehyde $(<0.3 \mathrm{mM})$ are attainable in vivo in rat liver after acute ethanol administration, the higher levels ( $\cong 2 \mathrm{mM}$ ) can be reached only with simultaneous disulfiram or pyrogallol treatment. In the experiments with broken cell preparations, higher concentrations (>7.5 mM) of acetaldehyde were required to consistently elicit displacement of PLP and enhancement of PLP degradation. The reason for this is unclear, but it should be emphasized that in many reports of experiments in vitro (35-37), high concentrations of acetaldehyde approaching or in excess of $1 \mathrm{mM}$ are required to demonstrate its toxic potentials. It is difficult to reconstruct in vitro with cell-free system the situation in vivo, because the exposure to acetaldehyde in man is chronic. Chronic ethanol consumption also results in higher blood acetaldehyde level due to imbalance between acetaldehyde production and disposition (38).

The decrease of PLP content in isolated hepatocytes due to low levels of acetaldehyde $(0.3 \mathrm{mM}$ and less) 
is about $20 \%$. This decrement, albeit small, is important in the overall economy of vitamin $B_{6}$ metabolism and $\mathbf{B}_{\mathbf{6}}$-dependent pathways. In a recent study (39), growing rats that were provided $4 \mu \mathrm{g}$ pyridoxine/day exhibited only a $20 \%$ decrease in liver PLP. However, these animals were vitamin $B_{6}$ deficient as evidenced by retardation of growth. The liver plays a control role in vitamin $B_{6}$ metabolism (40). It actively converts pyridoxine to PLP, pyridoxal, and pyridoxic acid which are released into the circulation (41). Whereas pyridoxic acid is biologically inactive, PLP and pyridoxal are the transport forms in plasma. Ethanol oxidation lowers hepatic PLP and impairs the release of this coenzyme (5). As shown here, acetaldehyde also decreases hepatic PLP; however, its effect on the release of PLP and pyridoxal has not been defined.

The deleterious effect of ethanol-derived acetaldehyde on PLP metabolism may be mediated by additional mechanisms. In liver and other tissues, acetaldehyde is oxidized to acetate. Acetate has been shown to inhibit the recombination of PLP with glutamate apodecarboxylase (42). Recently, Dietrich and Irwin (43) have suggested another effect of acetaldehyde, namely, the inhibition of the metabolic elimination of endogenous aldehydes more potent than acetaldehyde itself. These toxic endogenous aldehydes may include formaldehyde, malondialdehyde, and the biogenic aldehydes. The role of these aldehydes and acetate upon PLP binding and degradation awaits further study.

\section{ACKNOWLEDGMENTS}

The author wishes to thank Dr. Ting-Kai Li for his advice and suggestions.

This work was supported by the Veterans Administration grant 5246.

\section{REFERENCES}

1. Hines, J. D., and D. H. Cowan. 1970. Studies on the pathogenesis of alcohol-induced sideroblastic bonemarrow abnormalities. N. Engl. J. Med. 283: 441-446.

2. Mitchell, D., C. Wagner, W. Stone, G. H. Wilkinson, and S. Schenker. 1976. Abnormal regulation of plasma pyridoxal 5'-phosphate in patients with liver disease. Gastroenterology. 71: 1043-1049.

3. Lumeng, L., and T-K. Li. 1974. Vitamin $B_{6}$ metabolism in chronic alcohol abuse: pyridoxal phosphate levels in plasma and the effects of acetaldehyde on pyridoxal phosphate synthesis and degradation in human erythrocytes. J. Clin. Invest. 53: 693-704.

4. Lumeng, L., R. E. Brashear, and T-K. Li. 1974. Pyridoxal 5'-phosphate in plasma: source, transport and metabolic fate. J. Lab. Clin. Med. 84: 334-343.

5. Veitch, R. L., L. Lumeng, and T-K. Li. 1975. Vitamin $B_{6}$ metabolism in chronic alcohol abuse: the effect of ethanol oxidation on hepatic pyridoxal s'-phosphate meetabolism. J. Clin. Invest. 55: 1026-1032.

6. Li, T-K., L. Lumeng, and R. L. Veitch. 1974. Regulation of pyridoxal 5'-phosphate metabolism in liver. Biochem. Biophys. Res. Commun. 61: 677-684.

7. Deitrich, R. A., P. A. Troxell, W. S. Worth, and V. G. Erwin. 1976. Inhibition of aldehyde dehydrogenase in brain and liver by cyanamide. Biochem. Pharmacol. 25: 2733-2737.

8. Seglen, P. O. 1972. Preparation of rat liver cells. I. Effect of $\mathrm{Ca}^{2+}$ on enzymatic dispersion of isolated, perfused liver. Exp. Cell Res. 74: 450-454.

9. Edmondson, J. W., L. Lumeng, and T-K. Li. 1977. Calcium as a determinant of hepatocyte function. Clin. Res. 25: 561A. (Abstr.)

10. Edmondson, J. W., L. Lumeng, and T-K. Li. 1977. Direct measurement of active transport systems for alanine in freshly isolated rat liver cells. Biochem. Biophys. Res. Commun. 76: 751-757.

11. Lumeng, L. 1976. In vitro stimulation of ornithine decarboxylase activity by glucagon in isolated hepatocytes and the effect of ethanol. Fed. Proc. 35: 1733. (Abstr.)

12. Hogeboom, G. H. 1955. Fractionation of cell components of animal tissues. Methods Enzymol. 1: 16-19.

13. Ray, T. K. 1970. A modified method for the isolation of the plasma membrane from rat liver. Biochim. Biophys. Acta. 196: 1-9.

14. Granner, D. K., and G. M. Tomkins. 1970. Tyrosine aminotransferase (rat liver). Methods Enzymol. 17A: 633-637.

15. Hayashi, S-I., D. K. Granner, and G. M. Tomkins. 1967. Tyrosine aminotransferase. Purification and characterization. J. Biol. Chem. 242: 3998-4006.

16. Lundquist, F. 1974. Acetaldehyde: determination with aldehyde dehydrogenase. In Methods of Enzymatic Analysis. Vol. 3. H. U. Bergmeyer, editor. Academic Press, Inc., New York. 1509-1513.

17. Beutler, E. 1971. Red Cell Metabolism-A Manual of Biochemical Methods. Grune \& Stratton Inc., New York. 13.

18. Lowry, O. H., N. J. Rosebrough, A. L. Farr, and R. J. Randall. 1951. Protein measurement with the Folin phenol reagent. J. Biol. Chem. 193: 265-275.

19. Diamondstone, T. I. 1966. Assay of tyrosine transaminase activity by conversion of $p$-hydroxyphenylpyruvate to $p$-hydroxybenzaldehyde. Anal. Biochem. 16: 395-401.

20. Briggs, A. P. 1922. A colorimetric method for the determination of homogentisic acid in urine. J. Biol. Chem. 51: 453-454.

21. Bosron, W. F., R. L. Veitch, L. Lumeng, and T-K. Li. 1978. Subcellular localization and identification of pyridoxal 5'-phosphate-binding proteins in rat liver. J. Biol. Chem. 253: 1488-1492.

22. Lumeng, L., and T-K. Li. 1975. Characterization of the pyridoxal 5'-phosphate and pyridoxamine $5^{\prime}$-phosphate hydrolase activity in rat liver. J. Biol. Chem. 250: 8126-8131.

23. Borri Voltattorni, C., A. Orlacchio, A. Giartosio, F. Conti, and C. Turano. 1975. The binding of coenzymes and analogues of the substrate-coenzyme complex to tyrosine aminotransferase. Eur. J. Biochem. 53: 151-160.

24. Crow, K. E., N. W. Cornell, and R. L. Veech. 1977. The rate of ethanol metabolism in isolated rat hepatocytes. Clin. Exp. Res. 1: 43-47.

25. Lindros, K. O., R. Vihma, and O. A. Forsander. 1972. Utilization and metabolic effects of acetaldehyde and ethanol in the perfused rat liver. Biochem. J. 126: 945-952.

26. Eriksson, C. J. P. 1977. The distribution and metabolism of 
acetaldehyde in rats during ethanol oxidation. II. Regulation of the hepatic acetaldehyde level. Biochem. Pharmacol. 26: 249-252.

27. Fasella, P. 1967. Pyridoxal phosphate.Ann. Rev. Biochem. 36: 185-210.

28. Shaltiel, S., J. L. Hedrick, A. Pocker, and E. H. Fischer. 1969. Reconstitution of apophosphorylase with pyridoxal 5'-phosphate analogs. Biochemistry. 8: 5189-5196.

29. Madhusudanan Nair, P., and C. S. Vaidyanathan. 1964. A study of the purification and properties of tryptophan synthetase of Bengal Gram (Cicer arietinum). Arch. Biochem. Biophys. 104: 405-415.

30. Segel, I. H. 1975. Enzyme kinetics: behavior and analysis of rapid equilibrium and steady-state enzyme systems. John Wiley \& Sons Inc., New York. 957.

31. Pfeuffer, T., J. Ehrlich, and E. Helmreich. 1972. Role of pyridoxal 5'-phosphate in glycogen phosphorylase. II. Mode of binding of pyridoxal 5 '-phosphate and analogs of pyridoxal 5'-phosphate to apophosphorylase $b$ and the aggregation state of the reconstituted phosphorylase protiens. Biochemistry. 11: 2136-2145.

32. Eriksson, C. J. P., and H. W. Sippel. 1977. The distribution and metabolism of acetaldehyde in rats during ethanol oxidation. I. The distribution of acetaldehyde in liver, brain, blood and breath. Biochem. Pharmacol. 26: 241-247.

33. Truitt, E. B., Jr., and M. J. Walsh. 1971. The role of acetaldehyde in the actions of ethanol. In The Biology of Alcoholism. Vol. I. B. Kissin and H. Begleiter, editors. Plenum Publishing Corporations, New York. 161-195.

34. Collins, M. A., R. Gordon, Jr., M. G. Bigdeli, and J. A. Rubenstein. 1974. Pyrogallol potentiates acetaldehyde blood levels during ethanol oxidation in rats. Chem. Biol. Interactions. 8: 127-130.
35. Schreiber, S. S., K. Briden, M. Oratz, and M. A. Rothschild. 1972. Ethanol, acetaldehyde, and myocardial protein synthesis. J. Clin. Invest. 51: 2820-2826.

36. Cederbaum, A. I., C. S. Lieber, and E. Rubin. 1975. Effect of acetaldehyde on fatty acid oxidation and ketogenesis by hepatic mitochondria. Arch. Biochem. Biophys. 169: 29-41.

37. Cederbaum, A. I., C. S. Lieber, and E. Rubin. 1974. The effect of acetaldehyde on mitochondrial function. Arch Biochem. Biophys. 161: 26-39.

38. Lieber, C. S., Y. Hasumura, R. Teschke, S. Matsuzaki, and $M$. Korsten. 1975. The effect of chronic ethanol consumption on acetaldehyde metabolism. In The Role of Acetaldehyde in the Actions of Alcohol. K. O. Lindros and C. J. P. Eriksson, editors. The Finnish Foundation for Alcohol Studies, Helsinki. 83-104.

39. Lumeng, L., M. P. Ryan, and T-K. Li. 1978. Validation of the diagnostic value of plasma pyridoxal $5^{\prime}$-phosphate measurements in vitamin $B_{6}$ nutrition of the rat. J. Nutr. 108: 545-553.

40. $\mathrm{Li}, \mathrm{T}-\mathrm{K}$. 1978. Factors influencing vitamin $B_{6}$ requirement in alcoholism. In Human Vitamin $B_{6}$ Requirements. National Academy of Sciences, Washington, D. C. 210225.

41. Li, T-K., and L. Lumeng. 1977. Hepatic pyridoxine metabolism and its relationship to the plasma content of $\mathrm{B}_{6}$ vitamers. Clin. Res. 25: 572A. (Abstr.)

42. Fonda, M. L. 1975. The effect of anions on the interaction of pyridoxal phosphate with glutamate decarboxylase. Arch. Biochem. Biophys. 170: 670-697.

43. Deitrich, R. A., and V. G. Irwin. 1975. Involvement of biogenic amine metabolism in ethanol addiction. Fed. Proc. 34: 1962-1968. 